\title{
As variações lexicais para o conceito de "prostituta" no município de Anori-AM: um estudo dialetológico
}

\author{
Lexical variations related to the concept of "prostitute" from the \\ municipality of Anori-AM \\ Thays Coelho DE ARAÚJO* \\ Universidade Federal do Amazonas (UFAM) \\ Carolina Pinheiro BARROS ${ }^{* *}$ \\ Universidade do Sul de Santa Catarina(UNISUL)
}

\begin{abstract}
RESUMO: O presente trabalho é um estudo investigativo e comparativo sobre as variações lexicais relacionadas ao conceito de "prostituta", nas zonas urbana e rural do município de Anori, localizado no Amazonas. Desse modo, para compreender essas ocorrências, objetivou-se analisar as variantes lexicais encontradas para o conceito de "prostituta" na localidade selecionada. Para isso, analisamos a questão 142, pertencente ao campo semântico "convívio e comportamento social" do Atlas Linguístico do Brasil (ALiB). Por meio de uma pesquisa qualitativa e quantitativa, numa perspectiva diatópica, foram aplicados questionários com gravação de áudio, envolvendo 08 informantes, divididos entre a zona urbana e a zona rural de Anori. Teoricamente, esta pesquisa centra-se na Dialetologia e na Sociolinguística, por meio dos estudos de Cardoso (2010), Labov (2008), Feteiro e Silva (2015) e Bagno (2007). E, para tratar especificamente do léxico, abordamos os estudos de Polguère (2018), Henriques (2018), Caixêta (2015) e outros. Os resultados revelam que existem diferenças lexicais entre a zona urbana e a zona rural do município, pois em todos os casos, as variantes encontradas são predominantes em apenas um local, evidenciando, assim, a variação diatópica. Em suma, verificou-se que há uma diferença no comportamento da unidade lexical entre a zona urbana e a zona rural do município de Anori. Isso ocorre em razão de não ser analisado somente o critério de localização geográfica, mas também critérios sociais como faixa etária, grau de escolaridade e sexo.
\end{abstract}

PALAVRAS-CHAVE: Variação lexical. Variação diatópica. Conceito de prostituta. Município de Anori-Am.

ABSTRACT: The present work is an investigative and comparative study on lexical variations related to the concept of "prostitute", in the urban and rural areas of the municipality of Anori, located in the Amazon.Thus, to understand these occurrences, the objective was to analyze the lexical variants found for the concept of "prostitute" in the locality.For this, we analyzed question 142, belonging to the semantic field "conviviality and social behavior" of the Linguistic Atlas of Brazil (ALiB)Through a qualitative and quantitative research, from a

\footnotetext{
Mestre em Letras na área de Estudos da Linguagem pelo Programa de Pós-Graduação em Letras da UFAM. E-mail: haysaraujo19@ hotmail.com

** Doutoranda em Ciências da Linguagem pela Universidade do Sul de Santa Catarina (UNISUL), atuando na linha de Pesquisa Texto e Discurso. E-mail: callinda20@gmail.com
}

Revista Moara, n. 54, ago-dez 2019 ISSN: 0104-0944

Recebido em 19/09/2019

Avaliado em 19/10/2019 
diatopic perspective, questionares were applied with audio recording, involving 08 informants, between the urban area and the anori countryside. Theoretically, this research focuses on Dialectology and Sociolinguistics, through studies de Cardoso (2010), Labov (2008), Feteiro e Silva (2015) e Bagno (2007). And to deal specifically with the lexicon, we approach the studies of Polguère (2018), Henriques (2018), Caixêta (2015) and others.The results reveal that there are lexical differences between the urban area and the rural area of the municipality, because in all cases, the variants because in all cases, the variants found are predominant in only one site, thus evidencing the diatopic variation. In short, it was found that there is a difference in the behavior of the lexical unit between the urban area and the rural area of the municipality of Anori. This is because the criterion is not analyzed only geographic location, but also social criteria such as age group, educational level and gender.

KEYWORDS: Lexical variation. Diatopic variation. Concept of prostitute. Municipality of Anori-Am.

\section{Introdução}

A pesquisa dialetológica permite que conheçamos as características e tendências linguístico-culturais importantes para o registro e a valorização da identidade cultural de uma comunidade. Com isso, compreendemos que cada indivíduo utiliza uma forma particular de estabelecer o uso da língua em um ambiente de comunicação. Contudo, essa particularidade não quebra as regras pré-estabelecidas pela comunidade linguística, uma vez que se faz necessário estabelecer a comunicação entre os sujeitos de fala.

Dessa forma, as particularidades que cada participante de uma comunidade linguística apresenta se aplicam ao que chamamos de variação linguística. Essa variação pode ser encontrada nos níveis fonético-fonológico, sintático, morfológico, semânticolexical etc. Neste trabalho, aborda-se especificamente a variação no nível lexical da língua.

É certo que o léxico representa diversas realidades para uma localidade, entre elas estão os códigos de um determinado grupo e também a cultura de um povo. Nesse contexto, encontramos a variação lexical que apresenta o uso de diferentes palavras para expressar um conceito específico.

Com o propósito de estudar a língua de modo mais profundo em seu contexto de uso, surgiram os estudos da Sociolinguística Variacionista e da Dialetologia, que juntas buscam identificar as mudanças no campo da variação diatópica e diastrática. Esses estudos motivaram a criação do Atlas Linguístico do Brasil (ALIB), que contém dados

Recebido em 03/07/2019

Revista Moara, n. 54, ago-dez 2019 ISSN: 0104-0944 Avaliado em 19/10/2019 
coletados de diferentes regiões do Brasil, realizados por meio de questionários. Dessa forma, esses estudos possibilitaram um mapeamento de diversas variantes encontradas nas regiões do Brasil.

Para a realização deste estudo, buscaram-se explicações para as seguintes questões: quais as variantes encontradas para o conceito de "prostituta" no município de Anori-AM? Existem diferenças entre as variantes realizadas nas zonas urbana e rural do município escolhido? Em função disso, objetivamos identificar as variantes lexicais para o conceito de "prostituta". A pergunta do questionário semântico-lexical do (ALiB) que direcionou este estudo foi a questão 142: "como se chama a mulher que se vende para qualquer homem?" (ALIB, 2001). Essa questão faz parte do campo semântico "convívio e comportamento social" do ALIB. Desse modo, buscou-se analisar os dados coletados à luz da Dialetologia, comparando dados da cidade com dados da zona rural do município, no intuito de encontrar diferenças lexicais entre as localidades pesquisadas (critério diatópico) e identificando, quando possível, os fatores que motivam essa variação.

A relevância deste trabalho centra-se na apresentação de dados de uma localidade pouco, ou até mesmo nunca pesquisada, no que se refere a estudos sobre variação linguística, manifestada no nível lexical. Desse modo, contribui-se com dados inovadores nos estudos da área da Dialetologia. Além disso, ressalta-se a representação da cultura ribeirinha, que nem sempre é perpetuada, de modo escrito, para outras gerações.

Inicialmente, este trabalho apresenta uma reflexão sobre a variação linguística. Em seguida descreve o campo de investigação da Dialetologia monodimensional e pluridimensional. Posteriormente, delineia o escopo teórico das variações lexicais e diatópicas, por conseguinte, apresenta os procedimentos metodológicos utilizados na pesquisa e, por fim, a análise dos dados.

\section{Variação Linguística}

As diferentes maneiras de fala relacionam-se às transformações que decorrem nas línguas ao longo do tempo e, também, estão ligadas ao comportamento linguístico Recebido em 03/07/2019 
dos falantes de determinadas localidades. Essas diversas formas da fala, denomina-se variação linguística e mudança linguística, a mesma representou um marco histórico nos estudos e pesquisas linguísticas voltadas à ciência da linguagem. William Labov, um dos nomes mais proeminentes da sociolinguística, colaborou com suas pesquisas de natureza teórica e empírica para estudar os fenômenos linguísticos que envolvem a fala no seu processo extralinguístico.

No texto Fundamentos empíricos para uma teoria da mudança linguística. Labov juntamente com outros autores (WEINREICH; LABOV; HERZOG, 2006 [2012]), sustentam que na variação linguística, a

\begin{abstract}
língua funciona enquanto muda. (ii) A heterogeneidade não compromete o funcionamento da língua - um sistema homogêneo e invariável é que seria disfuncional em uma comunidade de fala culturalmente diversificada. (iii) A variação faz parte do sistema linguístico, que é heterogêneo e composto por regras e unidades variáveis. (iv) A variação é potencialmente a atualização, em cada momento que se considere a língua, dos processos de mudança em curso no seu devir histórico (mudança implica variação, mas variação não implica necessariamente mudança). (v) A variação não é aleatória. A análise sincrônica dos condicionamentos estruturais e sociais da variação é capaz de revelar os mecanismos que atuam na implementação dos processos de mudança que afetam o sistema da língua. (vi) A mudança linguística pode ser estudada diretamente através da análise da variação observada em cada estado de língua. (WEINREICH; LABOV; HERZOG, 2006 apud LUCHESI, 2012).
\end{abstract}

Devido ao fato das questões que envolvem a heterogeneidade da língua, ao ser usada de diversificadas formas essas variações não podem ser vistas como um erro. Ainda nessa reflexão sobre variações linguísticas, Tarallo (1986, p. 08) postula que as "variantes linguísticas são diversas maneiras de se dizer a mesma coisa em um mesmo contexto e com o mesmo valor de verdade. A um conjunto de variantes dá-se o nome de variável linguística". Nesse sentido, a Teoria da Variação cogita que a língua dentro de um contexto sociocultural, é uma forma de explicar a heterogeneidade que surge nos concretos usos extralinguísticos linguísticos.

Chambers (1995, p. 349), acredita que "a mudança é um tipo de variação linguística com propriedades sociais particulares", pois todo falante obtém conhecimentos de sua língua adquiridos no meio social, cultural etc. Esses conhecimentos se transformam em experiências linguísticas aprendidas numa comunidade de fala. O termo Comunidade de fala aqui, é entendida como "um grupo de pessoas que falam exatamente igual, mas que compartilham traços linguísticos que Recebido em 03/07/2019 
distinguem seu grupo de outros; comunicam relativamente mais entre si do que com os outros e, principalmente compartilham normas e atitudes diante do uso da linguagem" (cf. LABOV, 1972; GUY, 2000).

Com isso, compreendemos que são múltiplas as possibilidades de variação da língua, pois advém de uma sociedade que se transforma constantemente, impactando diretamente nos usos distintos que os falantes fazem da língua. Nesse contexto, Labov (2008, p. 150) acrescenta que "a comunidade de fala não é definida por nenhuma concordância marcada no uso de elementos linguísticos, mas sim pela participação num conjunto de normas partilhadas", ou seja, para o autor, as pessoas compartilham as normas que se empregam no uso da língua, numa comunidade (meio social) esses indivíduos não falam da mesma forma e isso nos mostra o caráter heterogêneo que a língua possui em uma dada comunidade de fala. Já

\begin{abstract}
a variação linguística é examinada em cinco eixos que ele considera mais importante no estudo da língua, especialmente do léxico. Ele explica os cinco eixos das variações que estão distribuídas da seguinte forma: Variação geográfica é a que está relacionada a regiões ou países específicos, a Variação de contexto de interação social, a que está relacionada ao ambiente em que o indivíduo cresceu; e Variação de temporalidade, também denominada de variação diacrônica, pois está relacionada às mudanças pelas quais a língua passa no decorrer do tempo. Posteriormente, o autor aborda sobre a Variação de campo de conhecimento, que é conhecida como língua utilizada em textos ou em uma conversa de caráter científico ou técnico e, por fim, a Variação diamésica, também conhecida como variação de modo de comunicação. Essa variação corresponde especialmente à distinção entre fala e escrita. (POLGUÉRE, 2018, p. 38).
\end{abstract}

Além da variação estar relacionada a esses cinco eixos apresentados, temos também as variações nos níveis morfológico, sintático, semântico e lexical etc. Estudar a heterogeneidade sistemática da língua, como propõe a Sociolinguística Variacionista, proporciona a compreensão das diversas formas linguísticas condicionadas por divergentes espaços geográficos, níveis de formalidade, classes sociais, comunidades, faixas etárias, dentre outros.

Portanto, não podemos analisar tais variações sem considerarmos os fatores extralinguísticos, aos quais estão inteiramente relacionados à variação. 


\title{
2. Dialetologia monodimensional e pluridimensional
}

Inicialmente, a Dialetologia voltou-se para a análise das diferenças geográficas, em uma visão monodimensional. No entanto, ao longo dos anos, passou por modificações e, hoje, alia-se informação diatópica às de enfoque social. Na história da Dialetologia tradicional, centrava-se em entrevistar apenas um único informante, principalmente: um homem adulto, com uma certa idade, de baixa escolaridade, que residisse em zonas rurais, nascido e criado neste lugar. Sendo assim,

\begin{abstract}
O pressuposto básico é que esse informante conhece melhor a cultura da comunidade e, consequentemente, pode ser o legítimo representante da variação do lugar. A baixa escolaridade é um critério que se justifica por conta de o informante ter menos capacidade de monitorar sua própria fala. Justamente por tomar o espaço areal como contexto para a investigação da fala, a dialetologia apresenta quadros multiformes da realidade linguística, em que a descrição da fala nos espaços geográficos constitui verdadeiros documentos do registro dos elementos que se unem à história, à cultura, aos percursos, aos trajetos no espaço e aos contatos entre as diferentes culturas. $\grave{A}$ Geolinguística ou geografia linguística cabe a tarefa de ser um método utilizado pela dialetologia (CORREA, 2012, p. 3).
\end{abstract}

Por intermédio destes aspectos ligados à dimensão tradicional, na escolha para algumas especificidades de informantes, se dá pela preferência aos núcleos com redes de pontos para zona rural, pois estas são localidades onde há uma das formas mais genuínas e antigas de fala. Pode ser explicada pela possibilidade de se retirar o léxico das palavras oriundas da zona rural por serem pouco viajados e possuir uma cultura totalmente genuína da terra.

Nesse tipo de Atlas considera-se, estudar as particularidades de uma língua de uma determinada área, em seu espaço geográfico. Para Altino (2007), “[...] um Atlas linguístico fornece uma imagem multidimensional, ele mostra onde e como se dão as variações no espaço físico e social". Neste caso, adere-se ao fato de um atlas ser considerado por monodimensional. Pois, o mesmo possui o interesse de cartografar apenas na dimensão diatópica, uma vez que os indivíduos se estabelecem nos espaços geográficos, constituindo, vínculos linguísticos de acordo com seus aspectos culturais. Tomamos como exemplos de atlas monodimensionais o APFB (Atlas Prévio dos Falares Baianos) e o EALMG (Esboço de um Atlas Linguístico de Minas Gerais), Recebido em 03/07/2019 
citados por Romano (2013, p. 217), pois "não apresentam na cartografia variáveis sociais, privilegiando a dimensão diatópica".

Apesar dessas duas correntes de estudos terem uma abordagem diferenciada, elas complementam-se, pois têm como foco o mesmo objeto de investigação: o dialeto. Tratemos o termo aqui, segundo o pensamento de (COSERIU, 1982, p. 11-12) onde os "dialetos se apresentam como subconjuntos da língua, possuem menos prestígio social e não causam ininteligibilidade entre os usuários da mesma língua”. Já, no pensamento de Dubois (1978, p.184) dialeto se apresenta como "uma forma de língua que tem o seu próprio sistema léxico, sintático e fonético, e que é usada num ambiente mais restrito que a própria língua”. E, em razão disso, iremos observar o vínculo que a dialetologia monodimensional e pluridimensional estabelecem com relação à pesquisa, pois essas vertentes têm como ótica de pesquisa o que afirma Justiniano (2012, p. 54): "a pesquisa dialetológica toma como base o espaço geográfico para evidenciar o que é característico de cada região, de cada localidade". A dialetologia que possui um caráter pluridimensional busca não somente evidenciar o que é característico de cada região ou localidade, mas também o que é característico de cada fator social.

De acordo com a autora, iremos compreender que as duas vertentes estão presentes para que o pesquisador possa escolher a qual delas a pesquisa se ajusta melhor. No entanto, é visível que não existe uma hierarquia entre ambas. A autora ressalta ainda que, por mais que exista uma similaridade entre essas duas possibilidades de pesquisas, o que determinará a função de ambas é a natureza dos dados que serão proferidos no escopo da pesquisa, ou seja, se os dados estão priorizando apenas um nível de abordagem da língua ou se traz comprovação de vários níveis.

Em suma, Cardoso (2010, p. 25) afirma que: “a dialetologia não pôde deixar passar ao largo a consideração de fatores extralinguísticos, inerentes aos falantes nem relegar o reconhecimento de suas implicações nos atos de fala". Com efeito, isso deu à dialetologia um caráter pluridimensional.

\subsection{Variação diatópica}

Recebido em 03/07/2019

Revista Moara, n. 54, ago-dez 2019 ISSN: 0104-0944

Avaliado em 19/10/2019 
Como já discutido anteriormente, a língua é heterogênea e não pode ser considerada invariável, pois esta não se apresenta como entidade homogênea, uma vez que é um produto social, Bagno (2007, p. 36) reforça que: “a língua é uma atividade social, um trabalho coletivo, empreendido por todos os seus falantes, cada vez que eles se põem a interagir por meio da fala ou da escrita".

Segundo Martins e Justiniano (2018, p. 22), “a nossa Língua Portuguesa constituise de um conjunto de variedades empregadas por seus falantes nas mais diferentes regiões do país”. Esse tipo de variação é chamado de diatópica, pois busca analisar falares de regiões e espaços físicos. Conforme Polguére (2018, p. 104), "a variação diatópica - manifesta-se através de diferenças linguística associadas a regiões ou países específicos".

No entanto, a variação diatópica não será encontrada apenas nesse contexto. É possível encontrá-la em uma mesma região, como bem explica Martins e Justiniano (2018, p. 22): “é possível perceber a variação diatópica dentro de uma mesma região, em que suas cidades também apresentam diversidade".

De acordo com os autores, é possível que, em uma mesma localidade, existam diversidades no falar, ou seja, uma linguagem urbana e uma linguagem rural. Por conseguinte, entendemos que os falantes de uma língua se articulam em sociedade, que a relação entre língua e sociedade não é fortuita e que o uso alternativo de formas linguísticas também não ocorre ocasionalmente. Supõe-se então que, neste caso, a influência de fatores estruturais, sociais e regionais que justifiquem as alternâncias de uso que ocorrem em áreas urbanas e rurais.

Considerando essa linha de pensamento, esta pesquisa analisará os seus dados à luz da Dialetologia, comparando dados da zona urbana e dados da zona rural do município de Anori, com o objetivo de encontrar diferenças lexicais nas localidades pesquisadas, estabelecendo, assim, um caráter diatópico.

\subsection{Variações lexicais}

Para compreendermos o aspecto linguístico que foi pesquisado, faz-se necessária uma breve abordagem do que é variação lexical. Sobre isso, Bagno (2007, p. 4) discorre

Recebido em 03/07/2019

Revista Moara, n. 54, ago-dez 2019 ISSN: 0104-0944 Avaliado em 19/10/2019 
que: "variação lexical: são palavras diferentes que expressam o mesmo sentido, ex: as palavras mijo, xixi e urina se referem todas à mesma coisa". Essas variações mencionadas pelo autor são executadas por vezes em diferentes regiões ou localidades.

Atualmente, os estudos acerca do léxico são inúmeros. E em muitos deles ainda se discute, em diversos trabalhos, a definição do termo. Entre algumas definições que o elucidam, vejamos a de Henriques (2018, p. 13, grifo do autor):

LÉXICO é o conjunto das palavras de uma língua, também chamadas de LEXIAS. As LEXIAS são unidades de características complexas cuja organização enunciativa é interdependente, ou seja, a sua textualização no tempo e no espaço obedece a certas combinações. Embora possa parecer um conjunto finito, o léxico de cada uma das línguas é tão rico e dinâmico que mesmo o melhor dos lexicólogos não seria capaz de enumerá-lo. Isto ocorre porque dele faz parte à totalidade das palavras, desde as preposições, conjunções ou interjeições, até os neologismos, regionalismos, passando pelas terminologias, pelas gírias, expressões idiomáticas e palavrões.

Dessa forma, compreendemos que o léxico de uma língua não tem uma dimensão e, por essa razão, constatamos que, por ser um conjunto de palavras bastante amplo, é viável que no léxico de uma língua ocorra variação em uma dada comunidade de fala.

Ainda discorrendo sobre o conceito de léxico, Bechara (2009, p. 88) explica que o léxico "é aquele significado que aponta para o que se apreende do mundo extralinguístico mediante a linguagem". Para o autor, esse termo é aplicado a todos os significados que surgem no mundo extralinguístico exposto pelos falantes de uma dada língua, em detrimento de haver uma capacidade inata de o falante atribuir significado a tudo que vê e o que sente.

Em muitos casos, o termo é confundido com vocabulário e por essa razão faz-se necessário diferenciá-los. Para isso, trazemos a contribuição de Polguére (2018, p.103), ao explicar que: “o léxico de uma língua é a entidade teórica que corresponde ao conjunto das lexias dessa língua". Enquanto "vocabulário é o subconjunto do léxico de uma dada língua que contém as lexias dessa língua que o indivíduo em questão domina". 
Para Biderman (2001, p.153), o léxico “[...] abrange todo o universo conceptual dessa língua e qualquer sistema léxico é a somatória de toda a experiência acumulada de uma sociedade e do acervo da sua cultura através das idades".

Em conformidade com essa afirmação, compreendemos que o léxico faz parte da experiência de uma sociedade e está relacionado à cultura de cada região, ou seja, cada região, através de sua cultura, tem sua forma de falar. Nesse sentido, ocorre a variação lexical advinda de diferentes falares e diferentes lugares. Por conseguinte, o que é bastante utilizado por um falante de uma determinada região é por vezes desconhecido por outros de outra região.

\section{Metodologia}

Neste trabalho, foi realizada uma pesquisa etnográfica de cunho qualiquantativo, tomando como modelo o questionário semântico-lexical (QSL) do projeto ALIB. Para a presente pesquisa, selecionamos a questão 142 do referido questionário: "como se chama a mulher que se vende para qualquer homem?", pergunta concernente ao conceito de "prostituta" encontrado no campo semântico "convívio e comportamento social" (ALIB, 2001). Abordou-se a variação de caráter diatópico, contudo, não foram descartadas as motivações de caráter social. Com isso, os critérios utilizados foram: local de residência, faixa etária, grau de escolaridade e sexo.

Foi escolhida uma amostra de 08 informantes, homens e mulheres, sendo 04 moradores da zona rural e 04 moradores da zona urbana. Na zona rural, foram feitos inquéritos com pessoas da Comunidade Liberdade II, pertencente aos limites do município de Anori. Todos os entrevistados nasceram na comunidade utilizada como ponto de inquérito. Segundo os critérios de faixa etária, classificamos em faixa etária I e faixa etária II. Para a faixa etária I, selecionamos informantes entre 18 e 30 anos e, para faixa etária II, selecionamos informantes entre 50 e 65 anos. Com relação à escolaridade, optamos por pessoas que possuem o Ensino fundamental II incompleto, escolaridade I, e Ensino médio incompleto, escolaridade II. Os quadros que caracterizam o perfil dos informantes foram organizados da seguinte forma: 
Quadro 1 - Identificação dos informantes da pesquisa, nome, local de residência, faixa etária, escolaridade e sexo

\begin{tabular}{|c|c|c|c|c|}
\hline Nome & Local & Faixa etária & Escolaridade & Sexo \\
\hline Informante 01 & Liberdade II & 18 e 30 anos & $\begin{array}{l}\text { Ensino Médio } \\
\text { (incompleto) }\end{array}$ & Feminino \\
\hline Informante 02 & Liberdade II & 18 e 30 anos & $\begin{array}{c}\text { Ensino } \\
\text { Fundamental } \\
\text { (Incompleto) }\end{array}$ & Masculino \\
\hline Informante 03 & Liberdade II & 50 e 65 anos & $\begin{array}{l}\text { Ensino Médio } \\
\text { (incompleto) }\end{array}$ & Feminino \\
\hline Informante 04 & Liberdade II & 50 e 65 anos & $\begin{array}{c}\text { Ensino } \\
\text { Fundamental } \\
\text { (Incompleto) }\end{array}$ & Masculino \\
\hline
\end{tabular}

Fonte: Santos (2019).

Dos 04 informantes encontrados na localidade Liberdade II, dois são jovens e dois são idosos, dos quais também 02 são do sexo feminino e 02 do sexo masculinos. Quanto à escolaridade, 02 possuem ensino médio incompleto e 02 possuem o ensino fundamental incompleto.

Quadro 2 - Identificação dos informantes da pesquisa, nome, local de residência, faixa etária, escolaridade e sexo

\begin{tabular}{|c|c|c|c|c|}
\hline Nome & Local & Faixa etária & Escolaridade & Sexo \\
\hline
\end{tabular}

Recebido em 03/07/2019

Revista Moara, n. 54, ago-dez 2019 ISSN: 0104-0944 Avaliado em 19/10/2019 


\begin{tabular}{|c|c|c|c|c|}
\hline Informante 05 & Zona urbana & 18 e 30 anos & Ensino Médio & Feminino \\
\hline Informante 06 & Zona urbana & 18 e 30 anos & $\begin{array}{c}\text { Ensino } \\
\text { Fundamental } \\
\text { (Incompleto) }\end{array}$ & Masculino \\
\hline Informante 07 & Zona urbana & 50 e 65 anos & $\begin{array}{l}\text { Ensino Médio } \\
\text { (Incompleto) }\end{array}$ & Feminino \\
\hline Informante 08 & Zona urbana & 50 e 65 anos & $\begin{array}{c}\text { Ensino } \\
\text { Fundamental } \\
\text { (Incompleto) }\end{array}$ & Masculino \\
\hline
\end{tabular}

Dos 04 informantes da zona urbana, encontramos 02 jovens e 02 idosos, dos quais 02 são do sexo feminino e 02 do sexo masculinos. Quanto à escolaridade, 02 possuem ensino médio incompleto e 02 possuem o ensino fundamental incompleto.

Os informantes responderam ao questionário aplicado por meio de uma entrevista com gravação de áudio, registrada através de um gravador de voz. Após esses procedimentos foram obtidos os dados com registros das variantes lexicais para o conceito escolhido. A partir de uma análise, teremos a identificação da motivação que leva o informante a utilizar essas variantes.

\section{Análise dos dados}

O conceito escolhido para análise pertence ao campo "convívio e comportamento social", trata-se da pergunta 142, do Questionário Semântico-Lexical (QSL), que se refere ao conceito de "prostituta": "a mulher que se vende para qualquer homem?" (ALIB, 2001). A palavra "prostituta" tem uma origem bem antiga e popularmente é conhecida como a "profissão mais antiga do mundo". Segundo o Dicionário de língua portuguesa Michaelis (1998), a palavra é definida como a mulher

Recebido em 03/07/2019

Revista Moara, n. 54, ago-dez 2019 ISSN: 0104-0944_ Avaliado em 19/10/2019 
que faz sexo por dinheiro. Contudo, a prostituição ainda é uma atividade estigmatizada, entendida socialmente como um comportamento desviante, marcado pela mercantilização do sexo e permeado por questões morais e religiosas que contribuem para o desprestígio da prática.

No contexto social, encontram-se inúmeras variantes para o conceito, muitas delas com particularidades que descrevem o comportamento do indivíduo, seja em uma única palavra, seja por vezes através de palavras compostas, mas que sempre buscam demonstrar características das pessoas com esse "perfil".

Assim, buscamos analisar as variantes lexicais encontradas nas zonas urbana e rural do município de Anori. No que tange à realização do inquérito, foi comum alguns informantes lidarem com a pergunta de forma cômica. Isso se deve ao fato do estigma social associado ao comportamento da mulher que pratica atividade sexual remunerada.

Ao todo, foram encontradas 07 variantes para o conceito escolhido. Segue o quadro com essas variantes e o número de vezes em que ocorreram na pesquisa.

Quadro 3 - As variantes com números de ocorrências

\begin{tabular}{|c|c|}
\hline Variantes & $\mathbf{N}^{\mathbf{o}}$ de ocorrência \\
\hline Rapariga & 1 \\
\hline piriguete & 1 \\
\hline vadia & 1 \\
\hline quenga & 1 \\
\hline prostituta & 1 \\
\hline puta & 1 \\
\hline putinha & 2 \\
\hline
\end{tabular}

Fonte: Santos (2019).

Todas as variantes foram encontradas em ambas as localidades, e algumas predominaram em apenas uma delas, como no caso das variantes "prostituta", "puta" e "putinha", que se apresentaram apenas na fala de informantes da zona urbana. Já com Recebido em 03/07/2019 Revista Moara, n. 54, ago-dez 2019 ISSN: 0104-0944 Avaliado em 19/10/2019 
relação às variantes "rapariga", "piriguete", "vadia" e "quenga", foram encontradas na fala de informantes da zona rural, totalizando uma variante para cada informante.

\section{Gráfico 1 - Ocorrências das variantes de prostituta em Anori-AM}

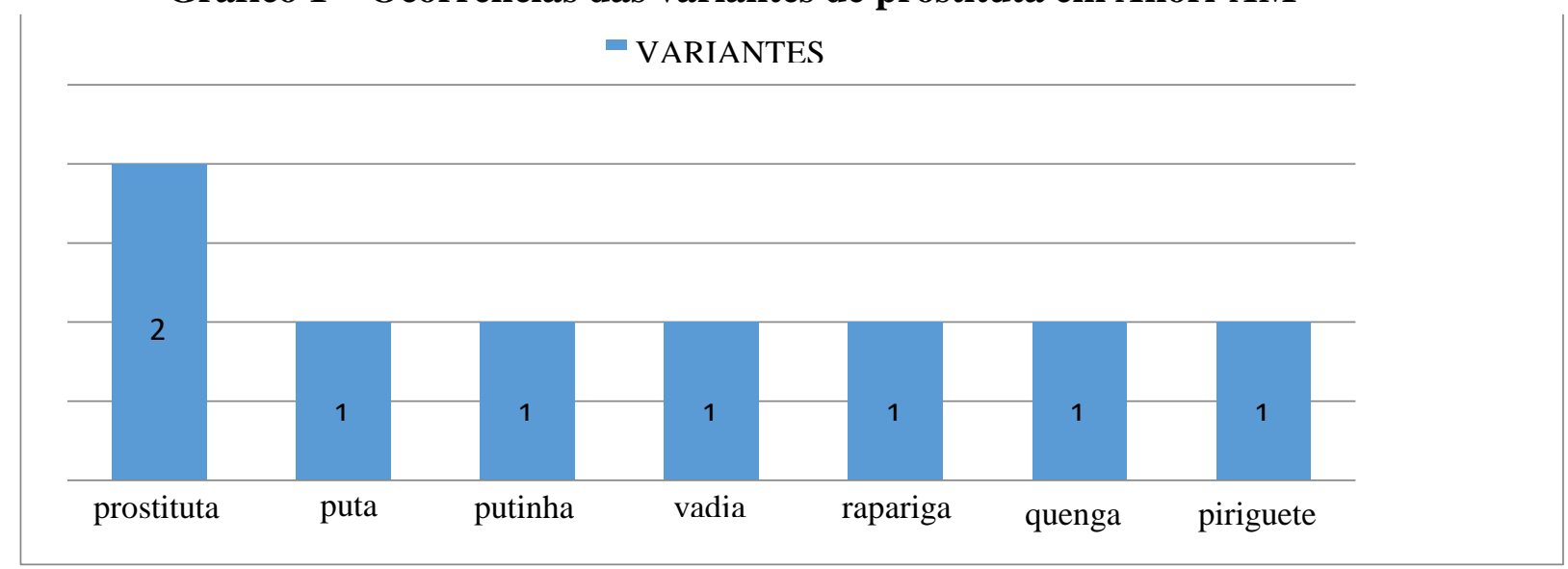

Fonte: Santos (2019).

Com base no Gráfico 1, constatamos que a variante lexical mais frequente no uso da língua falada nas localidades pesquisadas é "prostituta", constando $25 \%$ do total de ocorrências.

Essa variante foi falada por dois informantes moradores da zona urbana. Acrescenta-se a esses dados as variantes "puta" e "putinha" faladas por outros dois informantes da zona urbana. Isso nos mostra que o conceito de "prostituta" apresentou uma variação menor na área urbana. Vale acrescentar que na zona rural, todos os informantes fizeram uso de variantes diferentes, gerando assim quatro variantes lexicais, uma para cada informante, correspondendo a um percentual de $12,5 \%$ para cada variante.

No intuito de estabelecermos uma relação entre algumas variantes encontradas nos registros das variações da zona rural e suas motivações, foi consultado o dicionário Aurélio (2002), para pesquisarmos os significados das lexias "vadia", "rapariga", "quenga" e "piriguete". Assim sendo, de acordo com o Aurélio (2002, p. 855), a lexia "vadia" "significa andar ociosamente", já a lexia "rapariga" "refere-se à mulher nova", e 
a variante "piriguete" "é uma gíria na língua portuguesa que se refere a uma mulher provocadora que demonstra interesse por homens, isso ocorre mesmo que o sujeito esteja em um relacionamento", já a variante "quenga" "refere-se à coisa imprestável ou inútil”. É importante destacar que as variantes lexicais descritas são mais utilizadas pelos moradores da zona rural.

Vejamos um quadro que apresenta as variantes encontradas em ambas as localidades, aquelas que ocorreram apenas na zona rural e outras que ocorreram apenas na zona urbana.

Quadro 4 - Mostra das variantes por localidades

\begin{tabular}{|c|c|c|}
\hline $\begin{array}{c}\text { Zona Urbana e Zona } \\
\text { Rural }\end{array}$ & Zona Rural & Zona Urbana \\
\hline Prostituta & Vadia & Prostituta \\
\hline Puta & Rapariga & Puta \\
\hline Putinha & Quenga \\
\hline Vadia & Piriguete & \\
\hline Rapariga & & \\
\hline Quenga & & \\
\hline Piriguete & & \\
\hline
\end{tabular}

Fonte: Santos (2019).

Conforme os dados, verifica-se que as lexias "puta", "putinha" e "prostituta" ocorreram apenas na zona urbana. Por outro lado, notou-se uma diversidade maior de ocorrências para o conceito de "prostituta" por parte dos moradores da zona rural, o que resulta em uma variante para cada informante, sendo elas: "rapariga", "vadia", "quenga" e "piriguete". São registros que não se repetiram nas localidades.

Já com relação às motivações sociais, Cardoso (2010, p. 29) reforça que: “[...] a preocupação com as características sociais dos informantes e suas implicações no uso que fazem da língua não tem passado a margem dos objetivos da dialetologia". Com essa afirmação, compreendemos que os fatores sociais devem ser considerados em uma pesquisa dialetológica. Em suma, essas características sociais dos informantes e suas

Recebido em 03/07/2019

Revista Moara, n. 54, ago-dez 2019 ISSN: 0104-0944 Avaliado em 19/10/2019 
implicações no uso da língua são objetos de estudos da dialetologia pluridimensional. Dessa forma, faremos uma pequena demonstração de como esses fatores motivaram a realização das variantes em ambas as localidades. Na cidade, essas motivações sociais não exerceram estímulos significantes nos registros das ocorrências, já que "prostituta" foi realizada por informantes de diferentes sexos com a mesma faixa etária (faixa etária II) e mesmo grau de escolaridade (escolaridade II). Isso ocorreu também com as variantes "puta" e "putinha", que não variaram de forma significante: os informantes eram do mesmo grau de escolaridade (escolaridade I), com a mesma faixa etária (faixa etária I) e sexo diferentes.

Com relação aos registros de ocorrências nas zonas urbana e rural, percebeu-se que as motivações sociais exerceram fortes influências, pois para cada variável houve uma variante diferente. Isso demonstra que, além de haver variação diatópica entre as localidades, existem também variações causadas por motivações sociais.

\section{Considerações finais}

A presente pesquisa buscou trazer contribuições para a área dos estudos dialetológicos realizando uma pesquisa inovadora para o município escolhido. Os resultados obtidos ao longo da pesquisa trouxeram uma visão mais aprofundada de como o conceito de "prostituta" comporta-se nas localidades pesquisadas e também contribuíram para uma melhor compreensão do léxico e sua função em uma comunidade linguística.

Por se tratar da análise de um conceito pejorativo, no falar de indivíduos, percebeu-se que as lexias podem carregar em suas concepções a visão de mundo dos falantes de uma língua. Em razão disso, essas concepções podem refletir na fala de informantes das novas gerações que compartilham a mesma comunidade de fala, uma vez que informantes de faixa etárias diferentes realizaram a mesma variante durante a aplicação do inquérito.

A pesquisa teve como principal critério o caráter diatópico. Com isso, buscou-se encontrar diferenças no léxico de informantes da zona rural e da zona urbana e, por conseguinte, foram analisadas as variantes encontradas em ambas as localidades e,

Recebido em 03/07/2019

Revista Moara, n. 54, ago-dez 2019 ISSN: 0104-0944 Avaliado em 19/10/2019 
quando possível, as motivações sociais que faziam com que o falante realizasse determinada reprodução linguística. Ao fim da pesquisa, constataram-se diferenças significantes no que diz respeito às lexias registradas nas duas localidades. Nenhuma das variantes se repetiu nas duas localidades, todas elas foram realizadas em locais distintos.

Nas realizações dos informantes da zona rural, foi constatada uma variante para cada informante, resultando em quatro variantes para o conceito em questão. São registros que não se repetiram, ou seja, foram encontrados em uma quantidade mínima, isso nos leva a crer que os falantes da zona rural conhecem algumas lexias que não são conhecidas por informantes da zona urbana.

Espera-se, com este trabalho, incentivar pesquisas dialetológicas em localidades que ficam distantes de centros urbanos. Estas localidades conservam um riquíssimo acervo linguístico que pode servir como fonte de pesquisa e para a colaboração dos estudos dialetais no Brasil. Por tratar da variação lexical, este trabalho apresenta uma pequena possibilidade das inúmeras que podem ser abordadas em trabalhos na área da dialetologia, promovendo assim estudos cada vez mais significativos no que tange à variação lexical.

\section{REFERÊNCIAS}

Atlas Linguístico do Brasil: Questionários 2001/ Comitê Nacional do Projeto ALiB. Londrina: Ed. UEL, 2001.

BAGNO, Marcos. Nada na língua é por acaso: por uma pedagogia da variação linguística. 3ed. São Paulo: Parábola, 2007.

BIDERMAN, M. T. C. (2001). Teoria linguística: teoria lexical e linguística computacional. $2^{\mathrm{a}}$ ed. São Paulo: Martins Fontes.

BECHARA, Evanildo. Moderna Gramática Portuguesa. 38. Ed. São Paulo: Nova Fronteira, 2015

CARDOSO, Suzana Alice Marcelino. Geolinguística: tradição e modernidade. São Paulo: Parábola Editorial, 2010.

COELHO, Izete et al. Sociolinguística. Florianópolis: LLV/CCE/UFSC, 2010. 
FEITEIRO, Sandra Regina; SILVA, Socorro Cardoso. Estudo da Variação Lexical na Amazônia Paraense: um olhar sobre o Atlas Linguístico do Brasil. Signum. Londrina, n. 18/1, p. 157-181, jun. 2015

FERREIRA, Aurélio Buarque de Holanda. Miniaurélio: o dicionário da língua portuguesa. 8. ed. Curitiba: Positivo, 2010.

HENRIQUES, Claudio Cezar. Léxico e Semântica: Estudos produtivos sobre palavra significação. Rio de Janeiro: Alta Books, 2018.

JUSTINIANO, Jeiviane dos Santos. Atlas Linguístico dos Falares do Alto Rio Negro - ALFARiN. Dissertação (Mestrado em letras). Manaus: Universidade Federal do Amazonas, 2012.

LABOV, William. Padrões sociolinguísticos. São Paulo: Parábola Editorial, 2008.

MICHAELIS. Moderno dicionário da língua portuguesa. São Paulo: Companhia Melhoramentos, 1998.

MARTINS, Valteir; JUSTINIANO, Jeiviane; MARTINS, Silvana. Sociolinguística. Manaus: UEA, 2018.

POLGUÉRE, Alain. Lexicologia e semântica lexical: Noções fundamentais. São Paulo: Contexto, 2018. 